\title{
National survey of British public's views on use of identifiable medical data by the National Cancer Registry
}

Geraldine Barrett, Jackie A Cassell, Janet L Peacock, Michel P Coleman

\begin{abstract}
Objectives To describe the views of the British public on the use of personal medical data by the National Cancer Registry without individual consent, and to assess the relative importance attached by the public to personal privacy in relation to public health uses of identifiable health data. Design Cross sectional, face to face interview survey. Setting England, Wales, and Scotland.

Participants 2872 respondents, $97 \%$ of those who took part in the Office for National Statistics' omnibus survey, a national multistage probability sample, in March and April 2005 (response rates $62 \%$ and $69 \%$, respectively).

Results $72 \%$ (95\% confidence interval $70 \%$ to $74 \%$ ) of all respondents did not consider any of the following to be an invasion of their privacy by the National Cancer Registry: inclusion of postcode, inclusion of name and address, and the receipt of a letter inviting them to a research study on the basis of inclusion in the registry. Only $2 \%(2 \%$ to $3 \%)$ of the sample considered all of these to amount to an invasion of privacy. Logistic regression analysis showed that the proportions not concerned about invasion of privacy varied significantly by country, ethnicity, socioeconomic status, and housing tenure, although in all subgroups examined most respondents had no concerns. $81 \%$ (79\% to $83 \%)$ of all respondents said that they would support a law making cancer registration statutory.

Conclusions Most of the British public considers the confidential use of personal, identifiable patient information by the National Cancer Registry for the purposes of public health research and surveillance not to be an invasion of privacy.
\end{abstract}

\section{Introduction}

Epidemiological surveillance of the changing incidence, prevalence, and outcome of disease is essential for the delivery of effective health services and public health interventions. Since the year 2000, however, public health research has been disrupted because of a climate of concern about the ethics and legality of using identifiable data from patients' records..$^{1-4}$ Problems have resulted from new requirements to obtain consent from individual patients before information about them can be used in ways that were previously considered unremarkable-for instance, the inclusion of patient information in cancer registries, the compilation of information from databases for research projects, and the identification of appropriate patients by researchers for invitation to studies. Public health research requires information about the whole population, and biases arising from incomplete data can make the results unreliable, invalid, or misleading.
Current problems in the use of identifiable data for public health research in the United Kingdom are often attributed to the Data Protection Act 1998, but this is only partially accurate. The 1998 act implements the European directive on data protection, ${ }^{6}$ but its implementation has not caused problems in all European countries. ${ }^{7}$ The act codifies the conditions under which research can be done. It makes explicit provision for the use of identifiable data without individuals' consent for the "purposes of preventive medicine, medical diagnosis, the provision of care and treatment or the management of health-care services." This provision is subject to the data being processed by a health professional or person with an equivalent duty of confidentiality, and provided the information is not used to make decisions about the individual, will not cause substantial damage or distress, nor be published in a way that allows identification. Variable interpretations of the act (box 1$)^{8-10}$ have, however, led to a climate of uncertainty and difficulties in carrying out public health research. The position has been complicated by guidance from the General Medical Council ${ }^{11}$ and the NHS, ${ }^{12}$ and the creation of the Patient Information Advisory Group under the Health and Social Care Act 2001. ${ }^{13}$

The NHS code of practice on confidentiality states that it cannot be assumed that patients are happy for identifiable information about them to be used for purposes other than their direct care (box 2), ${ }^{12}$ but there has been relatively little research

\section{Box 1 Comments about the Data Protection Act 1998}

The 1998 act allows medical data to be used for any medical research purpose without the need for the consent of individuals. It is not necessary to define the term "medical research," nor to make specific provision for it to include the monitoring of public health, which for these purposes is regarded as medical research

Lord Falconer QC, Minister of State at the Cabinet Office, 2000

It is clear that many practitioners are confused between the requirements of the Data Protection Act and those of the various regulatory and representative bodies within the sector ... It is a common misconception, for instance, that the act always requires consent of data subjects to the processing of their data Elizabeth France, Information Commissioner, $2002^{9}$

The two most widely held misconceptions are that the act creates an overarching requirement to obtain explicit consent for the processing of all health data and that the requirements of the act are additional to good professional standards, medical ethics and confidentiality. In fact, in most cases the act will almost never require consent for the processing of data for research purposes, unless consent is also a more general legal requirement Phil Boyd, Information Commissioner's Office, $2003^{10}$ 
on patients' views. So far, no study has asked respondents to make a judgment about the balance between personal privacy and public health research.

We sought the views of the British public on the acceptability of identifiable information being used for public health purposes in the context of a real example. The National Cancer Registry collates data from nine regional cancer registries in England, with separate national registries in Scotland, Wales, and Northern Ireland. Data flows to the National Cancer Registry were disrupted after publication of new guidance from the General Medical Council in 2000, ${ }^{11}$ later revised. Data collection continues under section 60 of the Health and Social Care Act 2001 but this support is temporary. ${ }^{14}{ }^{15} \mathrm{~A}$ bill to make the registration of cancer a statutory requirement in England, Wales, and Northern Ireland is currently before parliament. ${ }^{16}$

\section{Methods}

We designed nine questions on cancer registration and personal privacy for inclusion in the omnibus survey run by the Office for National Statistics. We were inspired by a Canadian survey on the same topic (E Holowaty, personal communication, July 2002). Question 5 is based on the wording of the UK Department of Health website. ${ }^{17}$ We tested the questions using 29 cognitive interviews (data not shown). The final questions ensured that interviewees understood the purpose of the National Cancer Registry and that data transfers at the moment were without patients' consent. The omnibus survey team commented on the questions during development and approved their final form.

The questions were included in the March and April 2005 rounds of the omnibus survey, a national multistage probability cluster design survey. Of the 3000 addresses selected in March and the 2010 selected in April, 2762 and 1819, respectively, were eligible as they contained a private household. When addresses contained more than one household the National Office for Sta-

\section{Box 2 Extracts from the NHS code of practice on confidentiality}

Many current uses of confidential patient information do not contribute to or support the health care that a patient receives. Very often these other uses are extremely important and provide benefits to society-for example, medical research, protecting the health of the public, health service management, and financial audit. However, they are not directly associated with the health care that patients receive and we cannot assume that patients who seek health care are content for their information to be used in these ways.

Key identifiable information includes:

- Patient's name, address, full postcode, date of birth

- Pictures, photographs, videos, audiotapes, or other images of patients

- NHS number and local identifiable codes for patients

- Anything else that may be used to identify a patient directly or indirectly

For example, rare diseases, drug treatments, or statistical analyses which have very small numbers within a small population may allow individuals to be identified.

\section{Anonymised information}

This is information which does not identify an individual directly, and which cannot reasonably be used to determine identity. Anonymisation requires the removal of name, address, full postcode, and any other detail or combination of details that might support identification. ${ }^{12}$ tistics used a standard procedure to select one at random. In households with more than one adult, one person aged 16 or more was selected at random. If the person selected was unavailable or declined to be interviewed this was recorded as a non-response. Face to face interviews were carried out with 1703 people in March 2005 and 1252 people in April (response rates $62 \%$ and $69 \%$ ). We combined the data for analysis.

Analyses were carried out using Stata 9.0, taking account of the unequal probability of selection in households caused by varying household size and the increased standard errors associated with the clustering of interviews within postcode sectors. Proportions and 95\% confidence intervals are used to describe the estimates of opinion (weighted data shown, unweighted denominators given in tables) and to examine which factors are associated with support for cancer registration and with being unconcerned about invasion of privacy, the latter being a grouping of those who answered "no" to questions 7, 8, and 9. We entered into logistic regression models those factors with $\mathrm{P}$ values less than 0.05 in the unifactorial analyses. Results are presented as adjusted proportions.

\section{Results}

Of the 2955 interviewees, $2872(97 \%)$ answered all nine questions (table 1$)$. Thirty people $(1 \%)$ refused to answer the questions and a further $53(2 \%)$, a minority who completed telephone interviews, were asked none or only some of the questions. Table 2 shows the characteristics of respondents. Comparison with census data (not shown) showed that respondents were closely representative of the population, albeit with a small excess of owner occupiers. ${ }^{18}$

Most people $(n=2363,82 \%)$ had not heard of the National Cancer Registry but the vast majority $(n=2737,95 \%)$ thought that the information it collected was useful (questions 4 and 5, table 1). Over four fifths of responders $(n=2335,81 \%)$ said that they would support legislation to underpin the National Cancer Registry (question 6). Small but significant differences in levels of support were found according to age, ethnicity, socioeconomic status, housing tenure, and the experience of cancer in the immediate family. Only socioeconomic status and housing tenure remained significant after adjustment, with those living in rented accommodation and those of "not classified" socioeconomic status showing slightly lower levels of support (table 2).

Most respondents $(n=2740,95 \%)$ did not believe that a letter from their primary care trust inviting them to a cancer screening test was an invasion of privacy (question 3). Similarly, over $80 \%$ of respondents did not consider that the confidential inclusion of their postcode or name and address in the registry, or the receipt of a letter inviting them to take part in a research study, was an invasion of their privacy (questions 7 to 9). The scenario that caused most disquiet was the inclusion of name and address (question 8), with $16 \%$ of respondents $(n=446)$ considering this an invasion of privacy. In all, 2068 respondents (72\%, $95 \%$ confidence interval $70 \%$ to $74 \%$ ) indicated that none of these scenarios (inclusion of postcode in the registry, inclusion of name and address, and receipt of an invitation to a research study) was an invasion of privacy. Only 61 respondents (2\%, 2\% to $3 \%$ ) saw all three scenarios as an invasion of their privacy. The opinions of the other 714 respondents varied. Taking the opinion that none of the scenarios was an invasion of privacy as a marker of a lack of concern about invasion of privacy, small but significant differences were found according to country, ethnicity, socioeconomic status, housing tenure, and the experience of cancer in the immediate family. Each of these vari- 
Table 1 Respondents' views on cancer registration and privacy

\begin{tabular}{|c|c|c|c|c|c|c|}
\hline \multirow[b]{2}{*}{ Question } & \multicolumn{2}{|c|}{ "Yes" } & \multicolumn{2}{|c|}{ "No" } & \multicolumn{2}{|c|}{ "Don’t know" } \\
\hline & $\begin{array}{c}\text { No of } \\
\text { respondents* }\end{array}$ & $\%(95 \% \mathrm{Cl})$ & $\begin{array}{c}\text { No of } \\
\text { respondents* }\end{array}$ & $\%(95 \% \mathrm{CI})$ & $\begin{array}{c}\text { No of } \\
\text { respondents* }\end{array}$ & $\%(95 \% \mathrm{Cl})$ \\
\hline $\begin{array}{l}1 \text { To begin, could I please start by asking if you have, } \\
\text { or you have ever had, cancer? }\end{array}$ & 174 & 6 (5 to 7 ) & 2701 & 94 (93 to 95 ) & - & - \\
\hline $\begin{array}{l}2 \text { And have any members of your immediate family } \\
\text { (for instance, parents, children, } \\
\text { husband/wife/partner, brothers, sisters) ever had } \\
\text { cancer? }\end{array}$ & 1298 & 45 (43 to 47 ) & 1528 & 53 (51 to 56 ) & 50 & 2 (1 to 2 ) \\
\hline $\begin{array}{l}3 \text { Many people get letters from their primary care } \\
\text { trust (previously called the health authority) about } \\
\text { screening tests for cancer, such as cervical smear } \\
\text { tests or bowel cancer screening. If your primary } \\
\text { care trust sent you a letter inviting you to a } \\
\text { screening test, do you think this would be an } \\
\text { invasion of your privacy? }\end{array}$ & 93 & 3 (2 to 4) & 2740 & 95 (94 to 97) & 39 & 1 (1 to 2 ) \\
\hline $\begin{array}{l}4 \text { In the UK we have the National Cancer Registry, } \\
\text { which is a confidential NHS database of people who } \\
\text { have cancer. Have you ever heard of the National } \\
\text { Cancer Registry before? }\end{array}$ & 479 & 17 (15 to 18) & 2362 & 82 (81 to 84 ) & 32 & 1 (1 to 2 ) \\
\hline $\begin{array}{l}5 \text { The National Cancer Registry is the only reliable } \\
\text { source of information for monitoring trends in the } \\
\text { risk of getting cancer and trends in cancer survival. } \\
\text { The information is used to compare the } \\
\text { effectiveness of cancer treatment around the } \\
\text { country, and to evaluate the success of cancer } \\
\text { screening programmes. Do you think this is useful } \\
\text { information for us to have in this country? }\end{array}$ & 2737 & 95 (94 to 96 ) & 68 & 2 (2 to 3 ) & 69 & 2 (2 to 3 ) \\
\hline $\begin{array}{l}6 \text { In the USA, Denmark, Sweden, and many other } \\
\text { countries, all cases of cancer have to be notified to } \\
\text { the cancer registry by law. In future, there may } \\
\text { need to be a similar law in the UK, to ensure that } \\
\text { the National Cancer Registry continues to have the } \\
\text { information needed for monitoring cancer in the } \\
\text { UK. Would you support a new law that meant all } \\
\text { cases of cancer have to be notified to the National } \\
\text { Cancer Registry? }\end{array}$ & 2335 & 81 (79 to 83) & 343 & 12 (10 to 13 ) & 194 & 7 (6 to 8$)$ \\
\hline $\begin{array}{l}7 \text { Currently, cancer patients' postcodes are } \\
\text { automatically included in the National Cancer } \\
\text { Registry. This can help the registry tell, for } \\
\text { example, if cancer is related to living around } \\
\text { polluted areas. If you had cancer and your } \\
\text { postcode was included in the National Cancer } \\
\text { Registry, to be held confidentially and under strict } \\
\text { security, do you think this would be an invasion of } \\
\text { your privacy? }\end{array}$ & 243 & 8 (7 to 10$)$ & 2533 & 88 (87 to 90 ) & 98 & 3 (3 to 4$)$ \\
\hline $\begin{array}{l}8 \text { Currently, survival rates from cancer can only be } \\
\text { compared between regions of the country by } \\
\text { knowing cancer patients' names and addresses. If } \\
\text { you had cancer and your name and address was } \\
\text { included automatically in the National Cancer } \\
\text { Registry, to be held confidentially and under strict } \\
\text { security, do you think this would be an invasion of } \\
\text { your privacy? }\end{array}$ & 446 & 16 (14 to 17 ) & 2326 & 81 (79 to 83) & 101 & 4 (3 to 4$)$ \\
\hline $\begin{array}{l}\text { Finally, suppose that a research group from a } \\
\text { university medical school wanted to do research } \\
\text { with people who had a particular type of cancer. If } \\
\text { you had cancer and the National Cancer Registry } \\
\text { sent you a letter, via your doctor, asking if you } \\
\text { wanted to take part in the research, do you think } \\
\text { this would be an invasion of your privacy? }\end{array}$ & 261 & 9 (8 to 10$)$ & 2508 & 87 (86 to 89 ) & 104 & 4 (3 to 5$)$ \\
\hline
\end{tabular}

ables, except the experience of cancer in the family, remained significant after adjustment, with the Scottish, those whose ethnicity was not "white British," those of lower socioeconomic status, and those living in rented accommodation being more likely to be concerned about invasion of privacy (table 2).

\section{Discussion}

The majority of the British public does not consider the confidential use of personal, identifiable information by the National Cancer Registry for the purposes of public health research and surveillance to be an invasion of privacy.
Furthermore, four fifths of the public would support a law making cancer registration statutory.

An advantage of this study is that we were able to pose questions about the uses of identifiable patient information within the context of a real public health example, the National Cancer Registry. This allowed respondents to consider both the private good of privacy and the public good of public health information when formulating their answers. The survey was also a large scale national probability sample survey, carried out on our behalf by the Office for National Statistics, an independent government agency with an excellent reputation for survey quality and probity. 
Table 2 Factors associated with support for law on cancer registration and not being concerned about invasion of privacy

\begin{tabular}{|c|c|c|c|c|c|c|c|c|c|}
\hline \multirow[b]{2}{*}{ Variable } & \multirow{2}{*}{$\begin{array}{l}\text { No }(\%) \text { in } \\
\text { sample }\end{array}$} & \multicolumn{4}{|c|}{ Support for law on cancer registration } & \multicolumn{4}{|c|}{ Not concerned about invasion of privacy } \\
\hline & & $\begin{array}{l}\%(95 \% \mathrm{Cl}) \\
\text { support law }\end{array}$ & $P$ value & $\begin{array}{l}\text { Adjusted \% (95\% } \\
\text { CI) }{ }^{\star} \dagger\end{array}$ & $P$ value & $\begin{array}{c}\%(95 \% \mathrm{Cl}) \text { not } \\
\text { concerned }\end{array}$ & $P$ value & $\begin{array}{c}\text { Adjusted } \%(95 \% \\
\text { CI)** }\end{array}$ & $P$ value \\
\hline \multicolumn{10}{|l|}{ Sex: } \\
\hline Male & $1319(46)$ & 80 (77 to 83 ) & \multirow{2}{*}{0.284} & - & \multirow{2}{*}{-} & 73 (70 to 76$)$ & \multirow{2}{*}{0.462} & - & \multirow{2}{*}{-} \\
\hline Female & 1557 (54) & 82 (80 to 84 ) & & - & & 71 (68 to 74) & & - & \\
\hline \multicolumn{10}{|l|}{ Age group: } \\
\hline $16-44$ & $1315(46)$ & 79 (76 to 82$)$ & \multirow{3}{*}{0.040} & 80 (76 to 84 ) & \multirow{3}{*}{0.681} & 70 (67 to 73 ) & \multirow{3}{*}{0.154} & - & \multirow{3}{*}{-} \\
\hline $45-64$ & $997(35)$ & 84 (81 to 86$)$ & & 82 (77 to 86) & & 73 (70 to 77 ) & & - & \\
\hline$\geq 65$ & $564(20)$ & 82 (78 to 86) & & 81 (75 to 85) & & 74 (70 to 77 ) & & - & \\
\hline \multicolumn{10}{|l|}{ Country: } \\
\hline England & $2506(87)$ & 81 (79 to 83 ) & \multirow{3}{*}{0.136} & - & \multirow{3}{*}{-} & 72 (70 to 75$)$ & \multirow{3}{*}{0.005} & 75 (71 to 78$)$ & \multirow{3}{*}{0.004} \\
\hline Wales & $130(5)$ & 88 (80 to 94) & & - & & 79 (71 to 86 ) & & 81 (72 to 87 ) & \\
\hline Scotland & $240(8)$ & 77 (68 to 84$)$ & & - & & 62 (55 to 69) & & 65 (56 to 72 ) & \\
\hline \multicolumn{10}{|l|}{ Ethnicity: } \\
\hline White British & 2532 (88) & 82 (80 to 84 ) & \multirow{2}{*}{0.049} & 80 (76 to 84 ) & \multirow{2}{*}{0.293} & 73 (71 to 75$)$ & \multirow{2}{*}{$<0.001$} & 75 (71 to 78 ) & \multirow{2}{*}{0.002} \\
\hline All other groups & $335(12)$ & 76 (69 to 82) & & 76 (69 to 83) & & 63 (58 to 68) & & 66 (61 to 72 ) & \\
\hline \multicolumn{10}{|l|}{ Education: } \\
\hline Degree or higher & $542(19)$ & 79 (74 to 82) & \multirow{3}{*}{0.270} & & & 71 (67 to 75 ) & & & \\
\hline Below degree & $1496(52)$ & 82 (79 to 85) & & & - & 74 (71 to 77 ) & 0.086 & & \\
\hline No qualifications & $837(29)$ & 82 (78 to 85 ) & & & & 69 (65 to 73) & & & \\
\hline $\begin{array}{l}\text { Socioeconomic } \\
\text { status: }\end{array}$ & & & & & & & & & \\
\hline Managerial & 988 (34) & 81 (77 to 83) & & 80 (76 to 84$)$ & & 74 (71 to 76 ) & & 75 (71 to 78 ) & \\
\hline Intermediate & $588(20)$ & 85 (82 to 88$)$ & (200? & 85 (81 to 89$)$ & 0023 & 79 (75 to 82$)$ & 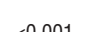 & 80 (75 to 84 ) & 0001 \\
\hline Manual & $1060(37)$ & 82 (79 to 85) & 0.002 & 83 (78 to 86 ) & $0.0<0$ & 69 (66 to 72) & $<0.001$ & 71 (67 to 75 ) & 0.001 \\
\hline Not classified & $240(8)$ & 72 (63 to 79$)$ & & 76 (67 to 83 ) & & 61 (54 to 68$)$ & & 66 (58 to 73 ) & \\
\hline Housing tenure: & & & & & & & & & \\
\hline Owner occupier & $2189(76)$ & 83 (81 to 85 ) & & 80 (76 to 84$)$ & & 74 (71 to 76 ) & & 75 (71 to 78 ) & \\
\hline Rents from local & 410 (14) & 77 (72 to 82) & & 74 (66 to 80 ) & & 64 (60 to 69) & & 68 (61 to 74$)$ & \\
\hline $\begin{array}{l}\text { authority or } \\
\text { housing } \\
\text { association }\end{array}$ & & & 0.001 & & 0.007 & & $<0.001$ & & 0.019 \\
\hline Rents privately & $275(10)$ & 74 (67 to 79 ) & & 73 (64 to 79 ) & & 67 (61 to 73) & & 71 (64 to 77 ) & \\
\hline Ever had cancer?: & & & & & & & & & \\
\hline No & 2701 (94) & 81 (79 to 83) & 0168 & - & & 72 (70 to 74 ) & 0012 & - & 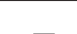 \\
\hline Yes & $174(6)$ & 85 (79 to 90$)$ & 0.168 & - & - & 72 (64 to 78 ) & 0.912 & - & - \\
\hline $\begin{array}{l}\text { Member of immediat } \\
\text { family ever had } \\
\text { cancer?: }\end{array}$ & & & & & & & & & \\
\hline No or don't know & $1578(55)$ & 80 (77 to 82 ) & & 80 (76 to 84$)$ & 0.150 & 70 (67 to 73$)$ & (1) & 75 (71 to 78$)$ & 0.10 \\
\hline Yes & $1298(45)$ & 83 (81 to 85$)$ & $0.0<0$ & 82 (78 to 86$)$ & 0.104 & 74 (71 to 77$)$ & 0.004 & 77 (74 to 81$)$ & 0.100 \\
\hline
\end{tabular}

${ }^{*}$ Adjusted for other variables in model; values adjusted to reference category.

†Denominators were 2870 unweighted and 2873 weighted.

†Denominators were 2862 unweighted and 2865 weighted.

One limitation of the study was that within the constraint of nine survey questions we were only able to concentrate on one context, the public health use of identifiable information relating to cancer. Cancer may be a topic that the public considers of particular importance or that evokes special sympathy in Britain. Information from other studies, however, suggests that the findings of this study may be more broadly generalisable. Two studies that examined rates of consent to health registers (the Canadian stroke network register ${ }^{19}$ and the paediatric intensive care audit network register in the United Kingdom ${ }^{20}$ ) found that obstacles to consent were primarily due to logistical problems in gaining access to patients to ask for consent; when it was possible to ask patients or their representatives for permission to use identifiable information, consent was almost always given. Research across the European Union has also shown that doctors and medical services are highly trusted with regard to their use of individuals' personal information, much more so than tax authorities, banks, employers, and insurance and credit card companies. ${ }^{21}$ This suggests that the confidential use of identifiable health information for research without individuals' consent has not so far damaged the public's trust.
We are aware of only one previous study in which the public was asked about their support for cancer registration. ${ }^{22}$ The study was commissioned by the former West German government at the time of proposed legislation in 1983. The findings were broadly similar to ours: $87 \%$ of the public thought it important to set up cancer registers, $78 \%$ reported that they would agree with their data being reported and analysed if they developed cancer, and $78 \%$ of the public, once fully informed, supported a new law for cancer registration.

A recent discussion paper by the British Medical Association advocated wider debate about the uses of identifiable health information, asking to whom such information belongs and who should benefit from its use- the authors, the data subjects, the wider community, or the state ${ }^{23}$ In the past few years, the assumption has gained ground that the public would wish primacy to be given to individual privacy over the public interest, ${ }^{3}{ }^{14}$ despite the lack of evidence on public opinion. The NHS code of practice on confidentiality asserts that it cannot be assumed that patients are happy for information about them to be used for purposes other than direct patient care. ${ }^{12}$ Our findings suggest the opposite- that is, one cannot assume that 
patients would be happy if their information was only used for direct patient care and not also for other purposes such as public health research and surveillance. It has been argued that although individual consent is suitable in a clinical context, it is neither adequate nor appropriate in relation to public policy, including decisions about the public health uses of identifiable data. ${ }^{24}$ Our findings provide a direct insight into public views and suggest strong support for the confidential use of identifiable data on cancer for public health purposes and for statutory cancer registration. Research on attitudes towards the public health uses of identifiable data on other diseases, and the stimulation of public debate, would both be desirable.

We thank Eric Holowaty and Terrence Sullivan (Ontario, Canada) for sharing their survey findings with us; Kate Melvin, freelance researcher, for her work on the pretesting interviews; the Office for National Statistics for its help in refining the survey questions; David Forman, David Brewster, and Barry Evans for their comments on an early version of the question relating to statutory cancer registration; and Mike Richards for his letter of support. Contributions: GB, MPC, and JAC designed the study. GB and MPC were responsible for the development and testing of the questions. All authors were involved in the analysis and interpretation of data and in writing the paper. GB is the guarantor.

Funding: Cancer Research UK (C18215/A5716).

Competing interests: None declared.

Ethical approval: Brunel University ethics committee.

\section{What is already known on this topic}

Most policies on the use of personal medical data assume that the public will prioritise individual privacy over public health uses of such data

Little evidence supports this assumption

Few studies have assessed public opinion on the uses of identifiable medical data, without consent, for health research and surveillance

\section{What this study adds}

The British public supports the use of identifiable cancer data without consent for public health research

Relatively few people were concerned about invasion of privacy in this context

The public strongly supports the National Cancer Registry and that cancer registration should be required by law
1 Wellcome Trust Public Health Working Group. Public health sciences: challenges and opportunities. London: Wellcome Trust, 2004.

2 Ingelfinger JR, Drazen JM. Registry research and medical privacy. N Engl J Med 2004;350:1452-3.

3 Peto J, Fletcher O, Gilham C. Data protection, informed consent, and research. BMJ 2004;328:1029-30.

4 Walley T. Using personal health information in medical research. BMJ 2006;332:130-1.

5 Data protection act 1998. London: Stationery Office, 1998.

6 European Union. Directive 95/46/EC of the European parliament and of the council of 24 October 1995 on the protection of individuals with regard to the processing of personal data and on the free movement of such data, 1995.

7 De Vet HC, Dekker JM, Van Veen EB, Olsen J. Access to data from European registries for epidemiological research: results from a survey by the International Epidemiologifor epidemiological research: results from a survey by the Internation
cal Association European Federation. Int J Epidemiol 2003;32:1114-5.

8 Falconer of Thoroton. Freedom of information bill (Hansard). 2000 Nov 14: col 261-5. 8 Falconer of Thoroton. Freedom of information bill (Hansard). 2000 Nov 14: col 261-5. Information Commissioner. Use and disclosure of health data: guidance on the applicatio
of the Data Protection Act 1998. Wilmslow: Cheshire, Information Commission, 2002.

Boyd P. Health research and the Data Protection Act 1998. J Health Serv Res Policy 2003;8(suppl 1):S1-7.

11 General Medical Council. Confidentiality: protecting and providing information. London: GMC, 2000.

12 Department of Health. Confidentiality: NHS code of practice. London: DoH, 2003.

13 Health and Social Care Act 2001. London: HMSO, 2001.

14 Higgins J. The Patient Information Advisory Group and the use of patient-identifiable data.J Health Serv Res Policy 2003;8(suppl 1):S1-11.

15 Denham J. Health and social care bill (standing committee E, Hansard). 2001 Feb 8: col 480

16 Registration of cancer bill [HL Bill 46]. 15 Mar 2005. www.publications.parliament.uk/ $\mathrm{pa} / \mathrm{ld} 200405 / \mathrm{ldbills} / 046 / 2005046 . \mathrm{htm}$ (accessed 24 Jan 2006).

17 Department of Health. The national cancer registration system. www.dh.gov.uk/ PolicyAndGuidance/HealthAndSocialCareTopics/Cancer/CancerArticle/fs/ en?CONTENT_ID = 4068586\&chk = Pi3WpT (accessed 24 Jan 2006).

18 Office for National Statistics. KS18 tenure: census 2001, key statistics for local authorities. www.statistics.gov.uk/statbase/ssdataset.asp?vlnk $=6579 \& M o r e=Y$ (accessed 24 Jan 2006).

19 Tu JV, Willison DJ, Silver FL, Fang J, Richards JA, Laupacis A, et al. Impracticability of informed consent in the registry of the Canadian Stroke Network. $N$ Engl J Med informed consent

20 McKinney PA, Jones S, Parslow R, Davey N, Darowski M, Chaudhry B, et al. A feasibility study of signed consent for the collection of patient identifiable information for a national paediatric clinical audit database. BMJ 2005;330:877-9.

21 European Commission Research Group. Data protection. Special barometer 196-wave 60.0. Brussels: Directorate General Press and Communication, 2003.

22 Psydata. Krebsregister-Krebsregistreierung: Die Einstellungen und Bereitschaften der Bevolkerung der Bundesrepublik [Cancer register-cancer registration: the attitudes and readiness of resident citizens of the Federal Republic]. Frankfurt: Psydata, Institute für Marketanalysen, Sozial und Mediaforschung, 1983.

23 British Medical Association. Confidentiality as part of a bigger picture-a discussion paper from the BMA. London: BMA, 2005.

24 O'Neill O. Some limits of informed consent. J Med Ethics 2003;29:4-7.

(Accepted 17 February 2006)

doi 10.1136/bmj.38805.473738.7C

School of Health Sciences and Social Care, Brunel University, Middlesex TW7 5DU

Geraldine Barrett lecturer in health studies

Janet L Peacock professor of health statistics

Department of Primary Care and Population Sciences, Royal Free and University College Medical School, University College London

Jackie A Cassell homorary senior clinical research fellow

Non-Communicable Disease Epidemiology Unit, London School of Hygiene and Tropical Medicine

Michel P Coleman professor of epidemiology and vital statistics

Correspondence to: G Barrett geraldine.barrett@brunel.ac.uk 